DOI: http://doi.org/10.4038/sljp.v22i1.8095

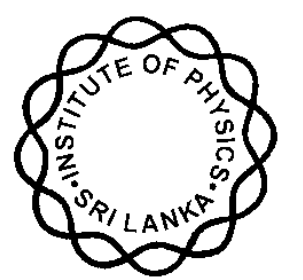

INSTITUTE OF PHYSICS - SRI LANKA

Research Article

\title{
The effect of surface plasmon resonance on the photovoltaic properties of CdS quantum dot sensitized solar cells
}

\author{
W.I. Sandamali 1,2, , G.K.R, Senadeera 1,2, ", M.A.K.L. Dissanayake ${ }^{2}$, T. Jaseetharan ${ }^{2,3}$ \\ V.P.S. Perera ${ }^{1}$, J.C.N. Rajendra ${ }^{1}$, N. Karthikeyan ${ }^{1}$ and L.A. Wijenayaka ${ }^{4}$ \\ ${ }^{1}$ Department of Physics, The Open University of Sri Lanka, Nawala, Nugegoda, Sri Lanka, \\ ${ }^{2}$ National Institute of Fundamental Studies, Hanthana Road, Kandy, Sri Lanka, \\ ${ }^{3}$ Department of Physical Sciences, Faculty of Applied Sciences, South Eastern University \\ of Sri Lanka, Sammanthurai, Sri Lanka, ${ }^{4}$ Department of Chemistry, The Open University of \\ Sri Lanka, Nawala, Nugegoda, Sri Lanka
}

\section{ABSTRACT}

Use of surface plasmon resonance effect of the Ag nanoparticles (Ag NPs) towards the photophysical properties of CdS quantum dot sensitized $\mathrm{TiO}_{2}$ based solar cells (QDSSCs) was investigated under the illumination of $100 \mathrm{~mW} \mathrm{~cm}^{-2}$ (AM 1.5). Depositions of CdS on $\mathrm{TiO}_{2}$ electrodes were carried out by successive ionic layer adsorption and reaction (SILAR) method with optimized ten cycles. Current voltage characteristics of QDSSCs fabricated with optimum amount of $\operatorname{Ag} \mathrm{NPs}(0.2 \% \mathrm{w} / \mathrm{v})$ in $\mathrm{TiO}_{2}$ showed $\sim 26 \%$ increment in the power conversion efficiency from 1.09 to $1.37 \%$. Surface morphological studies of photoanodes were carried out with scanning electron microscopy, high-resolution transition electron microscopy and energy dispersive X-ray measurements (EDX). The existence of spherical shape $\mathrm{Ag}$ nanoparticles in $\mathrm{TiO}_{2}$ with an average particle size of $35 \mathrm{~nm}$ was confirmed by EDX analysis. The estimated average size of the $\mathrm{TiO}_{2}$ and $\mathrm{CdS}$ particles appears to be around $40 \mathrm{~nm}$ and $4.2 \mathrm{~nm}$ respectively.

Keywords: Quantum dot sensitization, Ag nanoparticle, CdS, Surface plasmon resonance, $\mathrm{TiO}_{2}$ photoanode.

* Corresponding author: gksen@ou.ac.lk

https://orcid.org/0000-0002-9202-9008 


\section{INTRODUCTION}

Quantum dot (QD) sensitized solar cells (QDSSCs) are considered to be one of the promising alternative for low-cost next-generation photovoltaic devices due to the tunable band gap, high absorption coefficient and multiple exciton generation (MEG) of QDs. In QDSSCs, mesoporous $\mathrm{TiO}_{2}$ nanostructures which are usually fabricated on fluorine doped tin oxide (FTO) conducting glass substrates are sensitized with QDs. Among the QDs used as the sensitizers, CdS has attracted a great attention due to its excellent sensitizing ability in the visible regions of the solar spectrum [1-3]. It has been well established that metal nanoparticles (NPs), such as gold and silver can enhance the photovoltaic properties of QDSSCs due to their plasmon resonance effect (SPR) associated with the enhancement of electromagnetic field due to collective electron oscillation [4-5]. Further, these NPs can act as the light trapping agent and electron traps for facilitating charge separation. However, in most of the studies, scientists have investigated the effect of incorporation of nanoparticles into the wide band gap semiconductors like $\mathrm{TiO}_{2}$. In this scenario, SPR effect of Ag NPs on the $\mathrm{TiO}_{2}$ dye sensitized solar cell (DSSC) was extensively studied. In separate studies Saravanan et al [6] and Jeong et al [7] have reported the performance enhancement of DSSCs fabricated with silver nanoparticle incorporated $\mathrm{TiO}_{2}$ photoanodes. According to them, the photo current generation is enhanced due to the increase in the light trapping as a result of the SPR effect of the incorporated AgNPs in the photoanode and there by the enhancement of the overall performances of DSSCs. However, there are very few studies available on the usage of SPR effect on the quantum dot sensitized solar cells. Zhao et al has reported a highly efficient CdS/CdSe QDs sensitized solar cells by incorporating Ag NPs in to the $\mathrm{TiO}_{2} / \mathrm{ZnO}$ photoanode and observed an increase in light harvesting and a decrease in surface charge recombination while prolonging the electron life time [8]. However, according to our knowledge, there is no any evidence for QD sensitized solar cells with Ag NPs incorporated $\mathrm{TiO}_{2}$ electrodes sensitized with CdS photoanodes. In view of this, here, the possibility of use of SPR in the CdS quantum dot sensitized $\mathrm{TiO}_{2}$ based solar cells and its effect on the photo physical properties of the device have been explored. 


\section{EXPERIMENTAL}

\subsection{Preparation of Ag nanoparticles}

Silver nanoparticles were synthesized by using a facile one-pot chemical reduction method as described in the literature [9]. That is briefly by adding $0.25 \mathrm{~g}$ of $\mathrm{AgNO}_{3}$ (Sigma-Aldrich) to a $20 \mathrm{ml}$ of Di-methyl formaldehyde ( $>99 \%, \mathrm{BDH}),(\mathrm{DMF})$, containing $0.85 \mathrm{~g}$ of Polyvinyl pyrrolidine (PVP-40,000 M.W, BDH), PVP, at room temperature and heating the reaction mixture at $90{ }^{\circ} \mathrm{C}$ for $6 \mathrm{~h}$. Ag colloidal dispersions with red, blue and green colors were collected at different time intervals. Using acetone as the precipitating agent, colloidal Ag nanoparticles were centrifuged at $3000 \mathrm{rpm}$ and dispersed in ethanol to obtain $0.40 \%(\mathrm{~W} / \mathrm{V})$ Ag nanoparticle dispersion.

\subsection{Fabrication of $\mathrm{TiO}_{2}$ photoanodes}

In the preparation of photoanodes, at first, a compact layer of $\mathrm{TiO}_{2}(\mathrm{P} 90)$ was spin coated on pre-cleaned fluorine-doped, tin oxide (FTO) glass substrates ( $8 \Omega \mathrm{cm}-2$, Solarnoix) by using a mixture prepared with $\mathrm{TiO}_{2} \mathrm{P} 90$ (Evonik) powder and $\mathrm{HNO}_{3}$. Spin coating of this layer was done for 1 minute at $3000 \mathrm{rpm}$. The spin coated substrate was sintered at $450{ }^{\circ} \mathrm{C}$ for 45 minutes. Subsequently a coating of $\mathrm{TiO}_{2}$ P25 (Degussa), active layer was "doctor bladed" on the P90 layer of the above substrate by using a mixture of $0.25 \mathrm{~g}$ of $\mathrm{TiO}_{2} \mathrm{P} 25$ powder, 1 $\mathrm{ml}$ of $0.1 \mathrm{M} \mathrm{HNO}_{3}, 0.05 \mathrm{~g}$ of polyethylene glycol (99.8\%, Sigma-Aldrich) and 1 drop of triton X-100 (Sigma-Aldrich). Finally, the substrates with all these two layers were resintered at $450{ }^{\circ} \mathrm{C}$ for 45 minutes and allowed to cool down to room temperature. Different amounts of previously prepared silver NPs were drop casted on some of the above $\mathrm{TiO}_{2}$ photoanodes and dried at $100{ }^{\circ} \mathrm{C}$ for 45 minutes.

\subsection{Deposition of $\mathrm{CdS}$ on $\mathrm{TiO}_{2}$ photoanodes}

Sensitization of $\mathrm{TiO}_{2}$ photoanodes having the configurations of $\mathrm{FTO} / \mathrm{TiO}_{2}(\mathrm{P} 90) / \mathrm{TiO}_{2} \mathrm{P} 25$ and $\mathrm{FTO} / \mathrm{TiO}_{2}(\mathrm{P} 90) /\left(\mathrm{Ag}-\mathrm{TiO}_{2} \mathrm{P} 25\right)$ with $\mathrm{CdS}$ quantum dots were done by using Successive Ionic Layer Adsorption and Reaction (SILAR) method. The CdS quantum dots were deposited on the $\mathrm{TiO}_{2}$ photoanode by 10 SILAR cycles; one cycle consists of dipping the photoanode in cationic precursor solution for 1 minute, washing with distilled water, drying in air, again dipping in anionic precursor solution for 1 minute, washing with distilled water and drying in air. This was optimized by testing the photovoltaic properties of the devices 
with different cycles. Aqueous solutions of $0.1 \mathrm{M} \mathrm{CdCl}_{2}$ and $0.1 \mathrm{M} \mathrm{Na} 2 \mathrm{~S}$ were used as cationic and anionic precursor solutions respectively. Finally, the photoanode was heated at $100{ }^{\circ} \mathrm{C}$.

\subsection{Solar cell fabrication and characterization}

Above photoanodes with effective area of $0.25 \mathrm{~cm}^{2}$ were sandwiched with Pt coated FTO counter electrodes using steel clips and an appropriate amount of polysulfide electrolyte containing sulfide/polysulfide redox couple $\left(\mathrm{S}^{2-} / \mathrm{S}_{\mathrm{n}}{ }^{2-}\right)$, which was prepared by dissolving 2 M Sulfur, $0.5 \mathrm{M} \mathrm{Na}_{2} \mathrm{~S}$ and $0.2 \mathrm{M} \mathrm{KCl}$ in a mixture of deionized water and methanol to the ratio of $3: 7(\mathrm{v} / \mathrm{v})$ stirring until a clear solution was obtained. Current-voltage characterizations electrochemical impedance spectroscopy (EIS) characterizations of above QDSSCs were carried out under simulated light of $100 \mathrm{~mW} \mathrm{~cm}^{-2}$ with AM 1.5 filter by using Autolab PGSTAT128 N. In order to ensure the repeatability of the device performance, at least 10 solar cells from each type were fabricated and tested.

\subsection{Characterization of materials}

Fabricated $\mathrm{FTO} / \mathrm{TiO}_{2}$ photanodes were characterized by the following techniques. Highresolution transmission electron microscopy (HRTEM) imaging was carried out with a JEOL JEM-2100 TEM at an accelerating voltage of $200 \mathrm{kV}$. Energy dispersive X-ray (EDX) spectra were obtained from Ametek EDX module with Octane T Optima-60 EDX detector in TEM mode.

\subsection{RESULTS AND DISCUSSION}

\subsection{Surface morphological characterization}

Figs 1(a) and 1(b) show the HRTEM micrograph and EDX spectra of Ag nanoparticles used for the doping of $\mathrm{TiO}_{2}$ electrodes respectively. As can be seen form Fig 1 (a), silver nanoparticles are spherical in shape having smooth surface and are well dispersed. The average diameter of silver nanoparticles is found to be approximately $35 \mathrm{~nm}$. This image also shows that the produced nanoparticles have more or less narrow size distribution. Elemental composition analysis by EDX presented clearly by Fig 1 (b) confirmed the presence of Ag showing a strongest signal from silver (Ag) region. Apart from the Ag peaks additional peaks assigned to carbon can also be seeing in the figure. This could be due to the residual organic compounds used in the preparation of Ag nanoparticles. Therefore, the 
unusual large particle appears in the HRTEM micrograph (Fig 1a) could be correlated with these additional $\mathrm{C}$ peaks or due to an aggregate formed by the Ag NPs. The surface topology SEM image of $\mathrm{TiO}_{2}$ nanoparticle layer (P25) deposited on FTO with P90 layer is shown in Fig. 1 (c). The estimated size of the $\mathrm{TiO}_{2}$ particles appears to be around $40 \mathrm{~nm}$. Fig. 1 (d) shows the EDX analysis of the $\mathrm{TiO}_{2} \mathrm{P} 25$ layer and it confirms the presence of Ti as well as O with no any other element percent. While Fig. 1. (e) shows the SEM image of the surface of the Ag doped (0.3 w/v\%) $\mathrm{TiO}_{2}(\mathrm{P} 25)$, Fig. 1 (f) shows the EDX spectra of it. From the figure the crystallite sizes of prepared samples are found to be in the range of 40-45 nm which are not noticeably varied by the Ag-doping. The particles seems to be in spherical in shape but agglomerated in both cases bare and $0.2 \%$ Ag-doped $\mathrm{TiO}_{2}$.
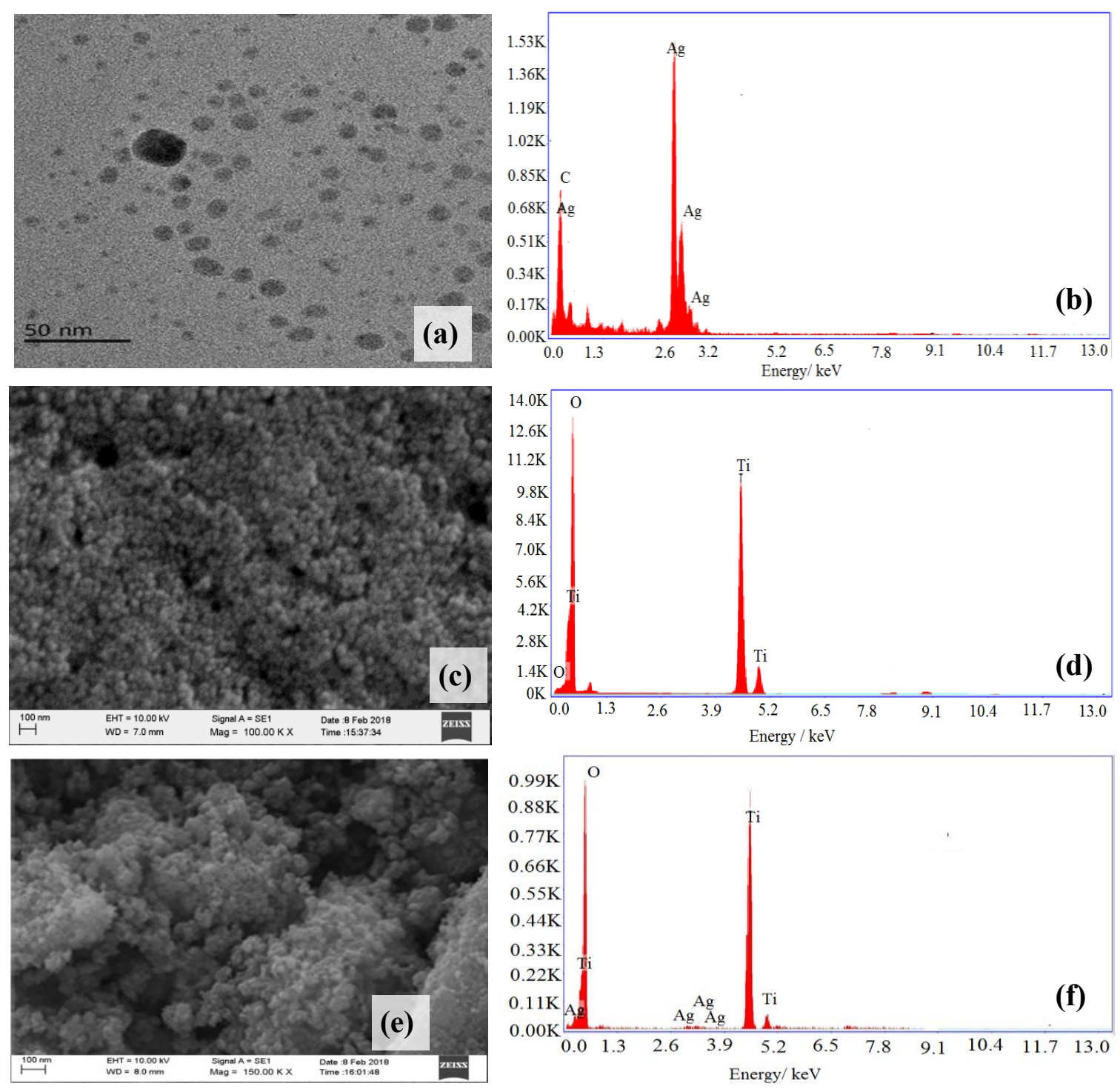

Fig.1 (a) HRTEM image and (b) EDX spectra of AgNPs, (c) SEM image and (d) EDX spectra of $\mathrm{TiO}_{2}$, (e) SEM image and (f) EDX spectra of $\mathrm{TiO}_{2} / \mathrm{AgNPs}$ 
SEM images of $\mathrm{Ag}-\mathrm{TiO}_{2}$ nanoparticles confirm the presence of porous, sponge-like structure and complexity. Such structure indicates the high surface area, resulting in greater adsorption of sensitizer, which has been proven to be useful for dye sensitized solar cells. Moreover, such a structure helps in the penetration of the electrolyte and expected to effectively enhance the efficiency [8-10]. Elemental determination by EDX analysis confirms the existence of $\mathrm{Ag}$ ion in $\mathrm{TiO}_{2}$.

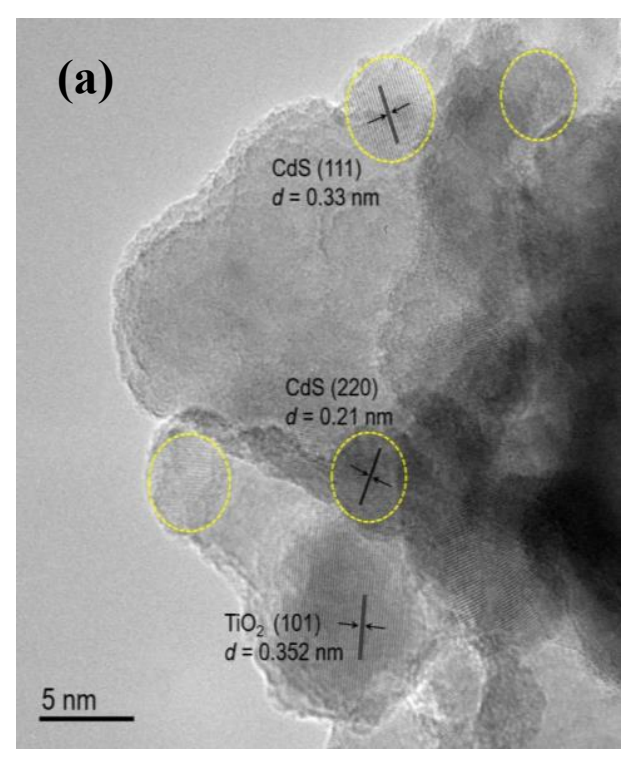

Fig. 2 (a) HRTEM micrograph and (b) EDX spectra of $\mathrm{TiO}_{2} / \mathrm{CdS}$

Fig. 2 (a) shows the HRTEM image of the CdS quantum dot-sensitized $\mathrm{TiO}_{2}$ electrode after 10 SILAR cycles. It can be seen that the size of the CdS quantum dots are in the range between 3.8 and $4.5 \mathrm{~nm}$. From the HRTEM image, the interplanar spacing $d$ were estimated as $0.33 \mathrm{~nm}$ and $0.21 \mathrm{~nm}$ which are associated to the $d$ values of (111) plane and (220) plane respectively.

\subsection{Current -voltage characteristics}

Fig. 3 shows the current- voltage characteristic of QDSSCs fabricated with $\mathrm{TiO}_{2} \mathrm{CdS}$ sensitized photoanodes without (1) and with (2) silver nanoparticles under above light conditions. As it is evident from the figure, significant enhancement can be seen in the photocurrent density $\left(J_{\mathrm{SC}}\right)$ of the device with silver NP treated $\mathrm{TiO}_{2} / \mathrm{CdS}$ photoanode with an increase in the photovoltage. The photovoltaic parameter estimated from Fig. 3 is tabulated in Table 1. 


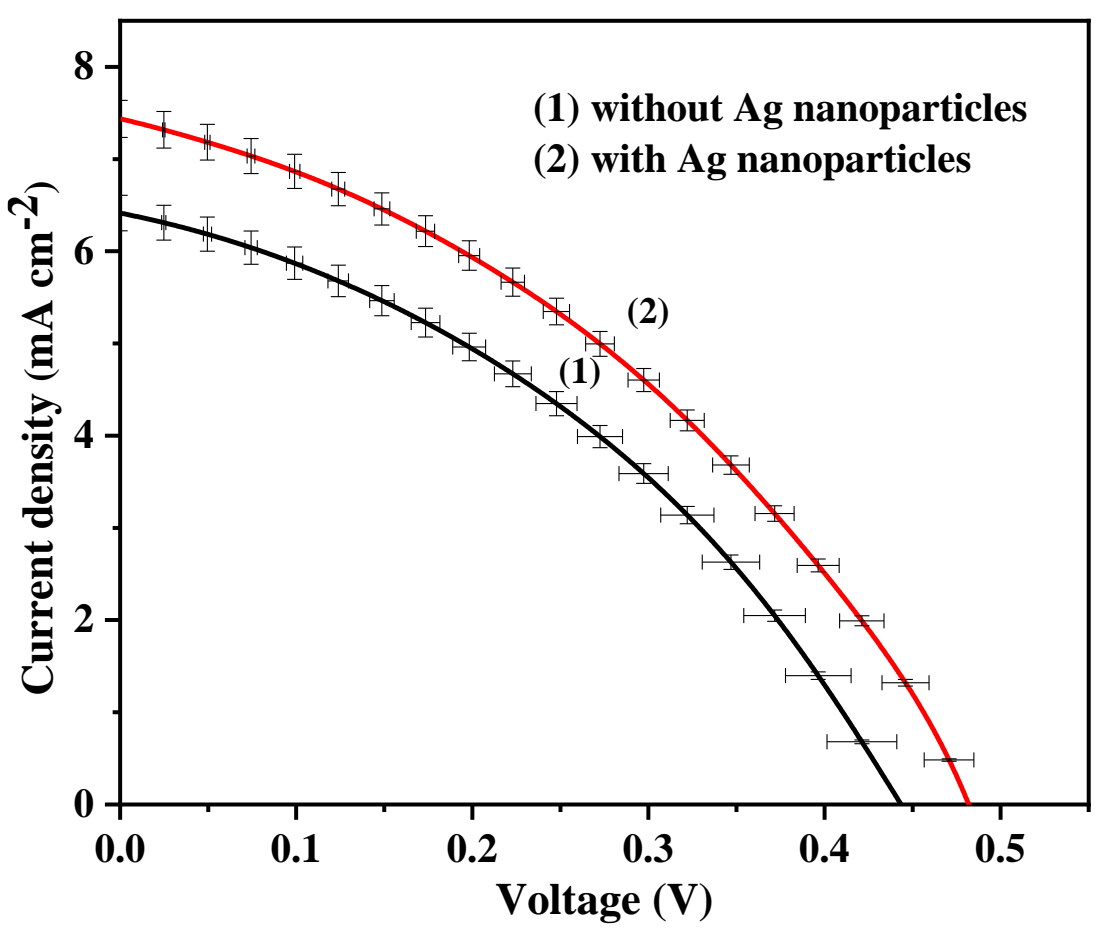

Fig. 3 Current - voltage characteristics of CdS QDSSCs fabricated with $\mathrm{TiO}_{2}$ photoanodes (1) without silver and (2) with silver NP. The curves represent the average current characteristics and the error bars represent the uncertainty of the current density and voltage measurements.

The enhancement of photovoltaic conversion efficiency, $\eta$ predominantly depends on the short-circuit-current density $J_{\mathrm{SC}}$, as shown in Table 1 .

Table 1: Photovoltaic parameters of CdS QDSSCs

\begin{tabular}{|c|c|c|c|c|c|}
\hline Photoanode & $\begin{array}{c}\text { Ag NP } \\
(\mathbf{2} \boldsymbol{\mu l})\end{array}$ & Voc (mV) & Jsc (mA) & FF (\%) & $\boldsymbol{\eta ( \% )}$ \\
\hline $\mathrm{TiO}_{2} / \mathrm{CdS}$ & $0 \%$ & 443.6 & 6.41 & 38.3 & 1.09 \\
\hline $\mathrm{TiO}_{2} / \mathrm{Ag} / \mathrm{CdS}$ & $0.1 \%(\mathrm{w} / \mathrm{v})$ & 482.0 & 6.73 & 40.37 & 1.31 \\
\hline $\mathbf{T i O}_{2} / \mathbf{A g} / \mathbf{C d S}$ & $\mathbf{0 . 2 \%}(\mathbf{w} / \mathbf{v})$ & $\mathbf{4 9 0 . 8}$ & $\mathbf{7 . 4 2}$ & $\mathbf{3 7 . 6 0}$ & $\mathbf{1 . 3 7}$ \\
\hline $\mathrm{TiO}_{2} / \mathrm{Ag} / \mathrm{CdS}$ & $0.3 \%(w / v)$ & 471.1 & 7.71 & 37.26 & 1.35 \\
\hline $\mathrm{TiO}_{2} / \mathrm{Ag} / \mathrm{CdS}$ & $0.4 \%(\mathrm{w} / \mathrm{v})$ & 461.2 & 5.37 & 36.66 & 0.90 \\
\hline
\end{tabular}

On the other hand, slight increase in the open circuit voltage $\left(V_{\mathrm{OC}}\right)$ can also be seen. This enhancement in $V_{\mathrm{OC}}$ could be due to the increase in the quasi-Fermi level in the $\mathrm{TiO}_{2}$ with the increase in the density of the electrons injected from quantum dots. QDSSCs fabricated 
with Ag NPs shows nearly $39 \%$ enhancement in the efficiency. This enhancement could be due to the increased amount of photo generated carriers between the QDs and $\mathrm{TiO}_{2}$ particles due to the SPR effect of Ag nanoparticles as observed by others in the cases of gold. It should be noted that the energy conversion efficiency of the CdS-sensitized solar devices fabricated with the present strategy is comparable and even higher than some of the efficiency values reported in the literature by using different strategies such as doping with different materials [7-11]. Therefore, it can be concluded that efficiency of CdS sensitized solar cells can be significantly enhance by incorporation of $\mathrm{Ag} \mathrm{NPs}$ in the $\mathrm{TiO}_{2}$ photoande with a simple techniques.

\section{CONCLUSIONS}

We developed $\mathrm{CdS}$ quantum dot (QD)-sensitized $\mathrm{TiO}_{2}$ photoanodes with effectively enhanced photovoltaic performance by using plasmatic silver nanoparticles and demonstrated that significant enhancement in the efficiency can be obtained by using this simple technique. As observed in dye sensitized solar cells, the light scattering and trapping of plasmonic silver nanoparticles and the near-field coupling of plasmonic silver with the $\mathrm{TiO}_{2}$ and $\mathrm{CdS}$ semiconductors could increase the effective path length of incident light in absorber layer and hence the efficiency of the device.

\section{ACKNOWLEDGEMENT}

This research was financially supported by the Research Grant awarded under the project of Development Oriented Research grants (DOR9-2019) under Accelerating Higher Education Expansion and Development (AHEAD) Operation of the Ministry of City planning, water Supply and Higher Education in Sri Lanka funded by the International Bank for Reconstruction and Development (IBRD) and International Development Agency (IDA).

\section{REFERENCES}

1. Sudhagar, P., Juárez-Pérez, E.J., Kang, Y.S. and Mora-Seró, I., (2014). Quantum DotSensitized Solar Cells. Green Energy and Technology, pp.89-136. DOI: https://doi.org/10.1007/978-1-4471-6473-9_5

2. Pan, Z., Rao, H., Mora-Seró, I., Bisquert, J. and Zhong, X., (2018). Quantum dotsensitized solar cells. Chemical Society Reviews, 47(20), pp.7659-7702. DOI: https://doi.org/10.1039/C8CS00431E 
3. Sahu, A., Garg, A. and Dixit, A., (2020). A review on quantum dot sensitized solar cells: Past, present and future towards carrier multiplication with a possibility for higher efficiency. Solar Energy, 203, pp. 210-239. DOI: https://doi.org/10.1016/j.solener.2020.04.044

4. Brown, M.D., Suteewong, T., Kumar, R.S.S., D’Innocenzo, V., Petrozza, A., Lee, M.M., Wiesner, U. and Snaith, H.J., (2011). Plasmonic Dye-Sensitized Solar Cells Using Core-Shell Metal-Insulator Nanoparticles. Nano Letters, 11(2), pp.438-445. DOI: https://doi.org/10.1021/nl1031106

5. Qi, J., Dang, X., Hammond, P.T. and Belcher, A.M., (2011). Highly Efficient PlasmonEnhanced Dye-Sensitized Solar Cells through Metal@Oxide Core-Shell Nanostructure. ACS Nano, 5(9), pp.7108-7116. DOI: https://doi.org/10.1021/nn201808g

6. Saravanan, S., Kato, R., Balamurugan, M., Kaushik, S. and Soga, T., (2017). Efficiency improvement in dye sensitized solar cells by the plasmonic effect of green synthesized silver nanoparticles. Journal of Science: Advanced Materials and Devices, 2(4), pp.418-424. DOI: https://doi.org/10.1016/j.jsamd.2017.10.004

7. Jeong, N.C., Prasittichai, C. and Hupp, J.T., (2011). Photocurrent Enhancement by Surface Plasmon Resonance of Silver Nanoparticles in Highly Porous Dye-Sensitized Solar Cells. Langmuir, 27(23), pp.14609-14614. DOI: https://doi.org/10.1021/la203557f

8. Zhao, H., Huang, F., Hou, J., Liu, Z., Wu, Q., Cao, H., Jing, Q., Peng, S. and Cao, G., (2016). Efficiency Enhancement of Quantum Dot Sensitized TiO2/ZnO Nanorod Arrays Solar Cells by Plasmonic Ag Nanoparticles. ACS Applied Materials \& Interfaces, 8(40), pp.26675-26682. DOI: https://doi.org/10.1021/acsami.6b06386

9. Joshi, D.N., Ilaiyaraja, P., Sudakar, C. and Prasath, R.A., (2018). Facile one-pot synthesis of multi-shaped silver nanoparticles with tunable ultra-broadband absorption for efficient light harvesting in dye-sensitized solar cells. Solar Energy Materials and Solar Cells, 185, pp.104-110. DOI: https://doi.org/10.1016/j.solmat.2018.05.018

10. Dissanayake, M.A.K.L., Jaseetharan, T., Senadeera, G.K.R. and Kumari, J.M.K.W., (2019). Efficiency enhancement in $\mathrm{PbS} / \mathrm{CdS}$ quantum dot-sensitized solar cells by plasmonic Ag nanoparticles. Journal of Solid State Electrochemistry, 24(2), pp.283292. DOI: https://doi.org/10.1007/s10008-019-04420-4

11. Dissanayake, M.A.K.L., Jaseetharan, T., Senadeera, G.K.R. and Thotawatthage, C.A., (2018). A novel, $\mathrm{PbS}: \mathrm{Hg}$ quantum dot-sensitized, highly efficient solar cell structure with triple layered TiO2 photoanode. Electrochimica Acta, 269, pp.172-179. DOI: https://doi.org/10.1016/j.electacta.2018.02.140 